\title{
A qualitative interview study on effects of diet on children's mental state and performance. Evaluation of perceptions, attitudes and beliefs of parents in four European countries
}

Brigitte Brands ${ }^{a}$, Bernadette Egan ${ }^{b}$, Eszter Györei ${ }^{c}$, Juan Carlos López-Robles ${ }^{d}$, Heather Gage ${ }^{b}$, Cristina Campoy ${ }^{d}$, Tamás Decsi ${ }^{c}$, Berthold Koletzko ${ }^{a}$, Monique M. Raats ${ }^{b}$

\author{
${ }^{a}$ Dr. von Hauner Children's Hospital, University of Munich Medical Centre, Lindwurmstr. 4, 80337 \\ Munich, Germany \\ ${ }^{b}$ Food, Consumer Behaviour and Health Research Centre, University of Surrey, GU2 7XH Guildford, \\ United Kingdom \\ c Department of Paediatrics, University of Pécs, József Attila Str. 7, H-7623 PÉCS, Hungary \\ ${ }^{d}$ Department of Paediatrics, School of Medicine, University of Granada, Avda. de Madrid, 11, 18012 \\ Granada, Spain
}

\begin{abstract}
Nutrition is one of the many factors that influence a child's cognitive development and performance. Understanding the relationship between nutrition and mental performance in children is important in terms of their attainment and productivity both in school and later life. Since parents are seen as nutritional gatekeepers for their children's diets, their views and beliefs are of crucial importance. The present study aims to qualitatively examine parents' perceptions of the relationship between diet and mental performance of children. The study was conducted with a total of 124 parents in four European countries using a semi-structured interview schedule. Parents speak of the effects of diet at two levels; the nature of the effects of diet and the characteristics of the foods responsible for these effects. Mental outcomes are related to diet, with the effects perceived to be associated with attention and concentration, often mediated by effects on children's mood and behaviour. Parents categorise foods as 'good' or 'bad' with positive effects related generally to a healthy balanced diet while negative effects are perceived to be associated with sugary and fatty foods. Understanding parental perceptions is important for many purposes including the targeting of dietary advice and prioritising of public health issues.
\end{abstract}




\section{Introduction}

Nutrition is one of a number of factors that may influence a child's development as well as genetic, socio-economic, environmental and behavioural factors. There is much interest in the role of nutrition in a child's physical development but understanding the relationship between nutrition and mental development and performance in children is equally important in terms of their attainment and productivity both in school and in later life (Alderman, Behrman, Lavy, \& Menon, 1997; Florence, Asbridge, \& Veugelers, 2008). Adequate nutrition in terms of recommended intake levels of macroand micronutrients is required for the development of the brain and therefore may influence the development of cognitive abilities (Bryan et al., 2004; Morley, 1998).

As the brain grows and develops throughout childhood, one might expect greater demands on the provision of nutrition during periods of rapid growth e.g. from the last trimester of pregnancy until 2 years of age, which if deficient could impair brain structure development (Benton, 2010). This could have long-term consequences for mental functioning. For instance, brain development during childhood includes that of the frontal lobes - nutrition could affect frontal lobe development, influencing the higher cognitive functions they control, such as focusing attention and inhibiting irrelevant stimulation (Bryan et al., 2004).

\section{The role of nutrients in brain development}

At a more detailed level, certain nutrients can affect brain cell integrity and structures, signal transduction and neurotransmission as well as brain energy supply and metabolism (Schmitt, Benton, \& Kallus, 2005). Micronutrients such as iron may play a critical role in cognitive development as well as in later performance (Thomas, Grant, \& Aubuchon-Endsley, 2009). A deficit in iron may result in decreased metabolic activity of brain cells which perturbs cognitive functions in the long term (Bourre, 2006a). Other micronutrients such as iodine and zinc are also considered to be of crucial importance. A deficiency of either iodine during critical periods of cerebral development induces a slowing of brain cell metabolic activity and permanent alterations in the development of the brain. lodine deficiency is anticipated to lower the IQ on average by 10-15 points at a general population level (Delange, 2001). Zinc plays a role in a multitude of molecular and physiological mechanisms, so even mild to moderate forms of zinc deficiency in children have been associated with reduced development and growth as well as impaired immune function (Bhutta et al., 1999; Brown, Peerson, Rivera, \& Allen, 2002). Vitamins also play a role in brain development and function, with all B-vitamins shown to be essential for normal functioning of the brain (Bourre, 2006a).

In terms of macronutrients, polyunsaturated fatty acids (PUFAs) omega-3 and omega-6, particularly Docosahexaenoic acid (DHA) and Eicosapentaenoic acid (EPA), are deemed to be of particular importance for brain development and function since the brain contains a large amount (60\%) of lipids (Bryan et al., 2004). Their main mechanism of action seems to be through the maintenance of cell membrane integrity and cell compartment functioning in the Central Nervous System (Bourre, 2006a). Proteins seem to be important during development but also for brain function, as the brain needs a sufficient supply of amino acids for the synthesis of certain neurotransmitters (e.g. catecholamines, serotonin). The quality of dietary proteins influences the nature and quantities of 
cerebral proteins and neurotransmitters. Since the human body does not possess a reserve for proteins, essential amino acids have to be acquired from food every day (Bourre, 2006b).

\section{The association between diet and cognitive functions}

In addition to affecting brain structure, nutrition may also affect cognitive function and performance. 'Cognitive functions' is a broad term used to represent a range of functions and processes associated with the brain, and these functions can be delineated into six main domains: perception, psychomotor functions, attention, memory and learning, language and executive functions (Schmitt et al., 2005), each of which also can be further subdivided into more specific modalities. These domains are closely interlinked and may also be modulated by a range of other factors including arousal, mood and motivation (Fig. 1). Several authors have reviewed the evidence for the influence of nutrition on cognitive functions (Bellisle et al., 1998; Benton, 2008a; Dye \& Blundell, 2002; Gibson \& Green, 2002) and indicate that measuring the effects of nutrition on mental state and performance is challenging, given the complex nature of cognitive functions, a range of confounding factors such as the time of day the measurement is made, or the composition of the foods used in interventions, and whether short-term or long-term effects are being examined. Various studies have investigated the effects of nutritional interventions across a range of cognitive domains, though principally attention and memory. Results from such studies include the findings that a carbohydrate-rich/protein-poor meal is sedating, while a protein-rich/ carbohydrate-poor meal tends to produce mental arousal and improved reaction times; facilitating a rise in blood glucose enhances performance of memory and reaction times (Dye \& Blundell, 2002). As well as direct effects on cognitive domains, the effects of nutrition may be mediated through changes in mood or arousal (Gibson \& Green, 2002).

Beyond specific nutrients and their role in cognitive development and function, eating behaviours such as skipping breakfast is considered to potentially contribute to poor mental performance (Pollitt \& Mathews, 1998). The effect of breakfast on cognitive performance may be by providing essential nutrients to the brain as well as alleviating hunger (Bellisle, 2004). A lack of energy leads to decreased glucose and insulin levels in the body which may be associated with impaired cognitive functioning (Benton, 2010). If such a lack of energy provision to the brain occurs frequently, it may be reflected in the level of school performance in the long run (Pollitt, 1995). Children and adolescents seem to be most likely to skip breakfast (Rampersaud, Pereira, Girard, Adams, \& Metzl, 2005) - an increased awareness of this has led to the initiation of school breakfast programmes in various European countries, especially in the UK. While skipping breakfast induces short term changes in metabolism, it may also affect overall nutritional status on a long term basis.

\section{Adverse effects of diet}

It is also important to consider the potential adverse effects of diet on brain function. In a review of the influence of children's diet on their cognition and behaviour, Benton (2008a) and Benton (2008b) comprehensively cover the potential links between children's behaviour and food intolerance, sucrose intake and additives in foods. Various studies have identified a range of foods and additives 
that may elicit adverse effects, including cow's milk, chocolate, wheat, grapes, the artificial colourant tartrazine and preservative sodium benzoate. Despite the common perception that sugar adversely influences behaviour e.g. in children with Attention-Deficit Hyperactivity Disorder (ADHD), there is little, if any, evidence of this (Benton, 2008a, 2008b; Ruxton, Gardner, \& McNnulty, 2010).

Overall it appears that brain function is sensitive to short-term variations in the availability of nutrients, with stronger findings for 'at-risk' groups (Pollitt, 1995). Thus, children should have a varied diet with good nutritional content and regular intake to ensure the best possible cognitive development and function (Bellisle, 2004; Florence et al., 2008; Tomlinson, Wilkinson, \& Wilkinson, 2009) since diet is providing both, the building blocks from which the brain is constructed and the fuel on which it runs (Benton, 2010).

The family is seen as one of the major contexts of a child's development which includes cognitive development and achievement (Scott-Jones, 1984) and specifically parents provide the environment in which young children develop knowledge, behaviours and values (Birch \& Davison, 2001). Parents influence all aspects of a child's life to some degree including the development of food choices as well as controlling the availability and types of food in the home (Brown \& Ogden, 2004; Golan \& Crow, 2004). Moreover, parents' own eating behaviours influence those of their children (Birch \& Davison, 2001) and thus the family provides a key environment for children to learn and develop food preferences and eating habits. Since parents are seen as nutritional gatekeepers, with responsibility for their children's diets, their views and beliefs are of crucial importance (Brown, Ogden, Vogele, \& Gibson, 2008).

To date there is little published research about the perceptions and awareness of parents regarding the relationship between nutrition and children's mental performance. Understanding parental perceptions of these relationships is important for many purposes including the development of policy and communication of nutritional information e.g. advice on the appropriate wording of claims. The purpose of the present study was to explore parental perceptions of the relationship between what children eat and their mental performance, and to compare and contrast their views with currently accepted expert models of the role of nutrition in mental performance.

\section{Methods}

Qualitative interviews were conducted with a total of 124 parents of children aged 4-10 years who were recruited through state schools in the cities and urban areas of Munich (Germany), Guildford (UK), Pécs (Hungary) and Granada (Spain). The four countries were selected to add strength to the study, reflecting diversity in both health and educational systems as well as differences in family attitudes to food and eating behaviours.

\section{Recruitment of participants}

Letters of invitation were sent to the Head Teachers of state schools in socio-economically different districts of each of the participating cities. In Germany, 1-3 schools from each of the 25 districts of Munich were randomly selected and 32 schools contacted, five schools from different districts 
committed to participate in the study. In England, a sample of state primary schools in the Guilford area was identified and twenty-two schools were approached of which four agreed to participate; subsequently two schools dropped out. In Hungary all 18 state schools were contacted and four schools confirmed their participation. In Spain, six public schools from different districts were contacted and one agreed to participate; a further two semi-private schools also agreed to take part in the study.

The participating schools in the four countries distributed letters to parents via their children. Parents were asked to volunteer to give a short interview by returning a brief screening questionnaire that collected contact details and socio-demographic background information. Participation was encouraged by entering the names of all volunteers in a prize draw for vouchers from a store of the winner's choice. Based on the socio-demographic data provided, parents were invited for interview from a variety of age groups, with different levels of education, and with children of different ages and genders. Inclusion criteria included the ability to speak the native language and being a parent of a child aged $4-10$ years. Parents of children with special educational needs or with a diagnosis of a medical or behavioural condition were excluded from the study. Background data collected included the number, ages and gender of participants' children, as well as their employment status and level of education. All data were recorded in a Statistical Package of the Social Sciences (SPSS) database.

Prior to conducting the interviews approval for the study was obtained from the relevant Ethics Committees in all four countries.

\section{Qualitative interviews}

A semi-structured interview schedule was developed, based on the aim of the study and relevant literature. A list of topics for the interview questions was agreed upon by the four participating countries and a preliminary interview format developed. Topics included questions on parents' beliefs and perceptions of the effects of diet on children aged 4-10, such as effects on wellbeing and development, physical and mental status, effects of specific foods on their mental or physical state as well as prompting for short or long term effects of diet and foods (Table 1). The preliminary schedule was translated and piloted in all countries to ensure that the type, flow and number of questions were appropriate to the aims of the study and to pre-test for clarity and comprehension. Transcripts of the pilot interviews were evaluated and compared and a final interview schedule agreed. Based on experiences with pilot interviews, the schedule also included revised prompts to aid interview progress when parents' answers were brief and to ensure that crucial points were covered.

Interviews were conducted with parents on school premises and lasted 15-20 min. All interviews were audio-taped with the interviewee's permission and transcribed verbatim. 


\section{Data analysis}

All transcripts were subjected to thematic analysis (Braun \& Clarke, 2006) using the software NVivo 8 (Welsh, 2002). Data were analysed primarily by researchers in the national languages in order to minimise the risk of losing participants' meanings and to present a comprehensive overview of the content of each data set at national level. Subsequently, a cross-national coding tree was developed which included definitions of each code to ensure standardised coding (Graneheim \& Lundman, 2004). Interview transcripts in each country were then analysed and detailed national reports, with supporting quotations, prepared in English for each country. Based on these national reports, key themes and relations were identified across the four countries for comparison in a final step resulting in a cross-national report. This report was systematically crosschecked in each country for appropriateness of interpretation and quotes by several researchers (B.B., B.E., E.G., J-CL-R) in order to increase the credibility and validity of the results, a process referred to as investigator triangulation (Patton, 1999). During the analysis, a particular emphasis was placed on examining parental perceptions of the relationship between food and mental performance.

\section{Results}

Between October 2008 and May 2009 a total of 124 face-to face interviews were conducted with parents in the four countries. The majority of parents interviewed were mothers except for Spain where approximately a fifth of participants were fathers (Table 2). Over half of the participants had a college degree or higher except for Spain where about $65 \%$ had a lower educational level. More than $60 \%$ of parents had two or three children while the rate of single child families was highest in Hungary compared to the other countries. Parents were responsible for choosing the food being served at home in all countries. More than $60 \%$ of participants were in paid employment at the time of the interviews while in Hungary this rate was $100 \%$.

A number of themes emerged from the analysis of the interviews regarding the relationship between diet and mental performance. Concerning diet, participants spoke of the characteristics of a healthy diet, characteristics of foods and drinks which constitute diet and the quantity and timing of foods and drinks. Regarding mental performance, the key findings relate primarily to attention, mood and behaviour (Fig. 2). In addition, the issue of hydration was identified as important in the German data. Details of the findings, which reflect the views of the majority of parents are presented, supported by relevant quotations from participants that best describe the findings.

Parents were initially asked the question if they thought diet had an effect on a child's wellbeing and development and if so in what way. Parents in all countries referred to a number of physical and mental outcomes which are associated with what children eat. In describing these outcomes, parents often mentioned their firsthand observations of the effects in their own children and also in the children of friends and relatives.

In all countries, the majority of parents were of the basic opinion that what a child eats affects their development, wellbeing and health:

"I strongly believe that there is a very close relationship between nutrition and development. We are what we eat". (Hungary - P03) 
"I am a great believer in you are what you eat so if you have burgers, burgers, burgers, honestly that would not be good for your health surely". (England - P03)

Many of the parents interviewed spoke initially in general terms about the relationship between what children eat and their development and only spoke of more specific effects of diet when probed. However more than half of the parents in England and Germany did refer to more specific physical and mental outcomes without probing, mentioning in particular hyperactivity, concentration and changes in behaviour linked to diet.

The effect of what children eat on their energy levels was one of the main outcomes referred to by the majority of participants in all four countries and was in turn seen to be closely related to the mental effects of diet. Food is perceived as being the source of a child's energy, with parents distinguishing between the effects of different types of foods and the amount of food consumed; e.g. having eaten too little or too much food results in tiredness and lethargy:

"Short term, it (the diet) could have an influence on all that we have been saying before, when you are in school for example, you notice the tiredness because sometimes they do not have the energy that they should"'. (Spain - P32)

"If we give fat rich stew to a smaller child, he will become full and he will suffer from tiredness. On the other hand, if we give some greens which are easier to digest then I think he will have enough energy and he will be more vigorous, able to play, to run [.. .]". (Hungary - P08)

Often parents seemed to be referring to 'mental energy' though generally they did not distinguish between this and what could be termed physical/biological energy, with only a handful of parents referring to alertness.

Across all countries the predominant aspects of mental performance to emerge were concentration and attention, as well as on a more general level, mental fitness and the feeling of well-being. For many of the parents the feeling of well-being achieved by a balanced and healthy diet seems to be a fundamental requirement for good performance.

"I am not a scientist but I believe in the saying a healthy mind is in a healthy body [...] we try in our family to have a varied diet and doing lot of physical exercise, too [.. .]". (Spain - P45)

"I think if they do not eat the food it will affect their concentration and if they are at school, those are times you need to concentrate, so your morning period, if you have eaten well in the morning you will be fine but then obviously in the afternoon if you do not eat properly your concentration's going to suffer". (England - P07)

While some parents spoke of the effects of diet in terms of a specific aspect of cognitive function, such as attention, others related the effect of diet to changes in mood and behaviour. Very often the effects of foods were perceived to be mediated by their effects on children's mood and behaviour, which in turn affected concentration and mental performance.

"Well when my children eat too many sweets, they get nervous and can not concentrate any more". (Germany - P07) 
"[.. .] with a balanced diet, rice, chicken fish [.. .] they are happy, they are sitting quietly and I have seen that their behaviour is quite nice after that". (England - P01)

Quite often parents used the terms diet, nutrition and food interchangeably and more rarely referred to specific nutrients. However for the majority of parents there was a very clear delineation between what they considered to be 'good' and 'bad' foods, with this categorisation based on the effects associated with these foods.

Parents in all four countries referred to the general concept of a healthy diet which involves balance, variety and moderation. This ideal diet should be fresh and natural as opposed to being ready made and containing artificial ingredients. Foods that form part of this ideal diet are described in such terms as good, healthy and often include meals that are home-cooked.

"Yes, everything should be covered [.. .] enough milk products, fruit and then also vegetables and every once and a while meat and also some sweet stuff. There should not be any prohibitions but it should all be balanced, not too much of one thing and too little of the other". (Germany - P47)

Parents associated positive effects on mental performance with a diet that is often described in general terms:

"I am a firm believer in a balanced diet of lots of fruit and vegs and the right types of food for their concentration during the day, slow release foods so I do not put biscuits and things in their lunchbox [.. . .". (England -- P14)

In contrast, parents referred to certain food in distinctly negative terms, being described as junk food, rubbish food, bad food or fast food. Unlike the general nature of positive foods, parents mentioned very specific foods in negative terms; including sugar, sweets, ready meals, processed foods and foods rich in fat:

"Obesity [.. .] much McDonalds and such a things can cause it, we do not eat there regularly, just occasionally, I fight against the fast foods, I cook, well". (Hungary-P06)

"Erm, obviously if they were to eat a load of what I consider to be junk foods, sweets and cakes and bits they obviously then are going to become obese, and again not willing to participate in exercise and things like that". (England - P03)

Most of the parents in all four countries considered foods rich in sugar as negatively influencing behaviour and mental performance. However, a clear dose-dependent relationship was attributed to sugar and its short term effects. Low sugar levels were perceived to result in a lack of energy, reducing mental performance in general and more specifically the ability to concentrate, whereas high sugar levels caused hyperactive behaviour and an inability to focus and concentrate.

"Well, as you know sugar makes them change a bit, for example when you give them a lot of sugar in the evening I have the feeling they are climbing up the walls". (Spain - P55)

"For instance, in my opinion, when a child is hypoglycaemic [.. . ] no matter if in school or in the afternoon when they return from school, from the after school care centres, and eat something at home, that they, that this gives back the ability to concentrate better again, for 
instance, or as I indicated earlier, the more sugar the more nervous. Well, this is really something that I can confirm". (Germany - P09)

Regarding meals, parents in all countries perceived breakfast to be important in terms of its effects on children's mental performance, particularly in the context of school performance.

"For example, if a child does not have breakfast in the morning or the wrong things for breakfast it may happen that after an hour or two in class, the child just does not perform as well as other children". (Spain - P26)

"Attention and concentration relates to whether they had breakfast or not, very significantly". (Hungary - P10)

"[.. .] but a good whole hearty breakfast will keep you full, in theory, until mid-morning but if you do not have breakfast it makes you lethargic and lacks concentration but also to a certain extent, can be good or bad, everything in moderation". (England - P02)

The majority of parents spoke of breakfast in these general terms, often referring to simply having breakfast as being important, without specifying what the nutritional composition of such a breakfast might be.

"[.. .] Well one says that when you have not had a good breakfast that you can not do good work. Well, I do think that it is important, I insist that they eat something for breakfast even though this might be very little". (Germany - P48)

"Breakfast, well it has always been said that it is very important: it is the first meal of the day and it has to be important, it gives you all the energy that you need throughout the dayhaving a good breakfast is very important". (Spain -P33)

In addition to the influence of types of food eaten, the amount of food consumed by children was perceived to be equally important in terms of its effects on their mental performance.

Having sufficient food was considered important and necessary both to alleviate hunger and to provide energy. Hunger was perceived to be a distraction and barrier to concentration and mental performance as well as causing bad moods. Eating too little potentially reduces mental performance either because children are being distracted by feelings of hunger or by a lack of energy which results in children being unable to concentrate and work.

"Yes, when you leave the house in the morning and haven't eaten something then I think that you can't concentrate because you are hungry and you can not concentrate on anything else and I also think that what you eat is important". (Germany - P34)

"Yes, I do because again if you are hungry, all you are thinking about is hunger. You are not concentrating". (England -43)

"If they are hungry, their thoughts focus on eating. If they are full or have eaten too much, they are sleepier or pay less attention". (Hungary - P19) 
In Germany and Hungary, the majority of parents mentioned that consuming junk foods, foods rich in fat or simply eating too much causes lethargy and thus decreases performance and the feeling of wellbeing. This was not mentioned by many of the English parents and even less so by Spanish parents.

"[.. .] Well they are so flabby, well when they are so [.. .] I have seen that once, when they have eaten too much or those fatty things and then meat, than they are so tired and lazy. Well, one [... .] Yes. You can see it that they don't have any motivation and get into a bad mood [.. .]". (Germany- P26)

In contrast to the other countries, German parents referred to a good level of hydration as being very important for good mental performance - a lack of hydration is perceived to result in mental lethargy or bad mood. Noticeably, German parents mention liquids in general rather than giving examples of what kind of liquids are seen to be positive or negative.

"[.. .] I think that simply a healthy mixture of all, all what the body needs should be in place. What I believe is very important are liquids and that enough is being drunk in order to.. . Yes, because it makes you floppy and tired when one doesn't drink enough, right?' (GermanyP14)

In summary across all four countries the majority of parents believe that there is a relationship between what children eat and their mental performance. The findings reveal that parents speak of the effects of diet on mental performance at two levels: the nature of the effects observed and the characteristics of foods responsible for these effects. More specifically parents observe diet affecting attention and concentration, both directly and indirectly; with the indirect effects of diet mediated by effects on children's mood and behaviour. Generally parents refer to the more immediate, shortterm effects of diet on brain function and attribute these effects primarily to the nature of the diet consumed. Parents distinguish between 'good' and 'bad' foods with this dichotomy related to the effects associated with these foods. The quantity of food consumed is also important, both in terms of the energy supplied and the alleviation of hunger. Hydration emerges as an important issue for German parents.

\section{Discussion}

Most of the research to date on parental perceptions of the effects of diet relates to physical outcomes such as obesity (Hart, Herriot, Bishop, \& Truby, 2003; Hesketh, Waters, Green, Salmon, \& Williams, 2005; Withall, Jago, \& Cross, 2009) with little published research on the effects of diet on mental outcomes. This study addressed the question as to whether parents relate diet to a child's mental performance, what their predominant perceptions and beliefs are about this relationship and how these compare to current expert models.

In terms of the effects of diet on mental performance, parents spoke predominantly of effects on "attention" and "concentration". Attention is a major cognitive process, which appears to underlie other abilities such as learning, memory or more complex mental abilities (Hughes \& Bryan, 2003). Numerous studies on the potential effects of nutrition on performance have used tasks which 
measured attention, though results are difficult to compare because of the heterogeneity of the studies. We can interpret concentration as sustained attention.

Although parents spoke of some direct effects of food on attention and concentration, quite often these effects were described as being mediated by effects on mood and behaviour. Mood is not in itself a cognitive function but an affective state, closely related to emotion (Westenhoefer et al., 2004). Mood is thus malleable and changes in mood associated with diet were quite clearly linked by parents to changes in mental performance. There is ample evidence of the effects of food on mood (Rogers, 1995), though many studies have focused on the effects on mood as the primary outcome, rather than the mediating effects of mood on changes in cognitive function.

Parents in all countries related the effects on mental performance to foods in specific ways; speaking about the characteristics and quantity of food and drinks. Positive effects are most often associated with children having a healthy balanced diet and positive foods such as fruits, vegetables and wholegrain products. Overall, there is a remarkable degree of similarity across the four countries regarding parent's concept of a healthy diet. This reflects the findings of a review of perceptions of healthy eating which reported considerable homogeneity across studies from different countries, involving different age groups, sexes and socio-economic status (Paquette, 2005).

Parents consistently represented a healthy diet as one encompassing balance, variety and moderation and including foods such as fruit and vegetables, with low levels of fat, salt and sugar. The quality aspects of food were also important with foods described as natural, fresh, homemade and unprocessed. Similar results were reported in a study of the meaning of healthy and unhealthy eating among adolescents where foods were described either in terms of food characteristics, using summary terms such as "right types of food" "natural stuff" or by naming specific foods or food groups (Croll, Neumark-Sztainer, \& Story, 2001).

Positive mental effects were perceived to be a longer term outcome of a healthy diet; in contrast negative effects were perceived to be more immediate and short term and associated with specific foods and nutrients. Parents named numerous foods that they considered to be unhealthy, many more than in the healthy category. These included sugar, fat chips, sweets, fast food, fizzy drinks and pizza.

Parents distinguished very clearly between good and bad foods and see the composition of a child's diet as crucial for their physical and mental wellbeing. In previous research on food evaluation and health it was found common for individuals to categorise foods according to a good-bad dichotomy, based on specific food qualities (Rozin, Ashmore, \& Markwith, 1996). In discussing "good" and "bad" foods parents often mentioned the importance of achieving an optimum balance and this is well illustrated by their perceptions of the effect of sugar.

Parents in all four countries spoke of sugar as having a dosedependent effect: having too little is associated with a lack of energy and low blood sugar levels which result in mental lethargy, tiredness, bad mood and the inability to concentrate. In contrast, having food containing high sugar levels leads to an excess of energy resulting in hyperactive behaviour and thus the inability to sit still and concentrate. From a scientific perspective, glucose is the primary source of energy for the human brain - an inadequate supply of glucose has been shown to result in a significant loss of mental function (Hoyland, Lawton, \& Dye, 2008). A high intake of sugar has been associated in 
several studies with behavioural problems and hyperactivity in children, particularly in those with Attention-Deficit Hyperactivity Disorder (ADHD), although the majority of controlled experimental studies were not able to support this hypothesis (Associate Parliamentary \& Health, 2008; Bellisle, 2004; Brown \& Ogden, 2004).

As diet is perceived to be the source of a child's energy, parents view a lack of food as having a significant effect on children's performance. In addition to the lack of energy resulting from not eating, feelings of hunger are perceived to be a barrier to a child's ability to concentrate and to perform well mentally. This is particularly relevant in the context of missing breakfast before school, although eating something for breakfast is perceived to be more important than its nutritional composition. Hunger and lack of breakfast have been shown as significant factors negatively affecting learning and academic achievement by studies assessing nutritional influences on mental performance in children (Florence et al., 2008; Grantham-McGregor, 2005; Hoyland et al., 2008; Hughes \& Bryan, 2003) .

The interviews highlight that parents' aim for children to have a constant supply of energy which in turn ensures a constant level of attention and concentration. Parents believe that this can be achieved by children having sufficient quantities of those foods which are constituents of a healthy balanced diet.

An important issue for the majority of German parents was the level of hydration of a child, which was perceived to play an important role in mental performance. Too little fluid intake during the school day is seen to be a major cause of lethargy and bad mood as well as the inability to concentrate. A negative effect of dehydration on cognitive functions of children has been shown by studies in the field (Bar-David, Urkin, \& Kozminsky, 2005; D'Anci, Constant, \& Rosenberg, 2006). This awareness of the importance of hydration may be due to public health initiatives in Germany that recommend good hydration of children in order to promote good physical and mental performance (e.g. public health initiative "Trinken im Unterricht" which promotes the availability of liquids at school and especially during classes, www.trinken-imunterricht.de).

The methodological approach in the present paper calls for some caution when interpreting the findings. Since participants volunteered for the study, the sample may not be representative of the community of parents in terms of socio-demographics, knowledge and awareness or other values. The majority of participants from the four countries were mothers and very similar in terms of education, age and gender, which limits the interpretation of the findings somewhat. Due to the qualitative nature of the data selection bias may have occurred, though there were standardised procedures to increase objectivity and reliability. However, the results do not claim to reflect an exhaustive census, but are useful for revealing meaningful findings which are being used as the basis for a quantitative study which should provide further insights from a more diverse sample.

In summary, parents of the 4-10 years old children in all four participating countries attest to a relationship between what children eat and their mental performance. The effects are perceived to be primarily on attention and concentration, often mediated by effects on mood and behaviour. Positive effects are associated with a healthy balanced diet with beneficial effects on feelings of wellbeing, mental fitness and performance; in contrast, parents perceive specific foods and nutrients as having negative effects on mental outcomes such as attention, concentration, mood and behaviour. 
In feeding their children parents strive to achieve an ideal optimal nutritional balance, which ensures that children can perform well, both in terms of development and performance.

Overall the effects of diet on mental performance reported by parents correlate in the main with those reported in the literature, as described earlier. Although parents focus mainly on a single aspect of cognition, attention, this is the domain often used to assess nutritional influences on performance. Similarly parents recognise the effects of diet on mood, which is considered a modulating factor of cognitive performance. Given the acknowledged complexity of assessing nutritional influences on cognitive performance, research on parental perceptions in this area is needed if policy and appropriate interventions are to be developed. Such research should provide valuable input to inform effective nutritional communication, education and public health initiatives where mental performance is an important outcome.

\section{References}

Alderman, H., Behrman, J. R., Lavy, V., Menon, R., (1997). Child Nutrition, Child Health, and School Enrollment. A Longitudinal Analysis.SSRN eLibrary. Associate Parliamentary, F., \& Health, F., (2008). The Links Between Diet and Behaviour. The influence of nutrition on mental health..

Bar-David, Y., Urkin, J., \& Kozminsky, E. (2005). The effect of voluntary dehydration on cognitive functions of elementary school children. Acta Paediatrica, 94(11), 1667-1673.

Bellisle, F. (2004). Effects of diet on behaviour and cognition in children. British Journal of Nutrition, 92(Suppl 2), S227-S232.

Bellisle, F., Blundell, J. E., Dye, L., Fantino, M., Fern, E., Fletcher, R. J., et al. (1998). Functional food science and behaviour and psychological functions. British Journal of Nutrition, 80(Suppl 1), S173193.

Benton, D. (2008a). The influence of children's diet on their cognition and behavior. [Article]. European Journal of Nutrition, 47, 25-37.

Benton, D. (2008b). Sucrose and behavioral problems. [Review]. Critical Reviews in Food Science and Nutrition, 48(5), 385-401.

Benton, D. (2010). The influence of dietary status on the cognitive performance of children. [Review]. Molecular Nutrition \& Food Research, 54(4), 457-470.

Bhutta, Z. A., Black, R. E., Brown, K. H., Gardner, J. M., Gore, S., Hidayat, A., et al. (1999). Prevention of diarrhea and pneumonia by zinc supplementation in children in developing countries. Pooled analysis of randomized controlled trials. Zinc Investigators' Collaborative Group. Journal of Pediatrics, 135(6), 689-697.

Birch, L. L., \& Davison, K. K. (2001). Family environmental factors influencing the developing behavioral controls of food intake and childhood overweight. Pediatrics Clinical North America, 48(4), 893-907. 
Bourre, J. M. (2006a). Effects of nutrients (in food) on the structure and function of the nervous system. Update on dietary requirements for brain. Part 1. Micronutrients. Journal of Nutrition Health and Aging, 10(5), 377-385.

Bourre, J. M. (2006b). Effects of nutrients (in food) on the structure and function of the nervous system. Update on dietary requirements for brain. Part 2. Macronutrients. Journal of Nutrition Health and Aging, 10(5), 386-399.

Braun, V., \& Clarke, V. (2006). Using thematic analysis in psychology. Qualitative Research in Psychology, 3(2), 77-101.

Brown, R., \& Ogden, J. (2004). Children's eating attitudes and behaviour. A study of the modelling and control theories of parental influence. Health Education and Research, 19(3), 261-271.

Brown, K. A., Ogden, J., Vogele, C., \& Gibson, E. L. (2008). The role of parental control practices in explaining children's diet and BMI. [Article]. Appetite, 50(2-3), 252-259.

Brown, K. H., Peerson, J. M., Rivera, J., \& Allen, L. H. (2002). Effect of supplemental zinc on the growth and serum zinc concentrations of prepubertal children. A meta-analysis of randomized controlled trials. American Journal of Clinical Nutrition, 75(6), 1062-1071.

Bryan, J., Osendarp, S., Hughes, D., Calvaresi, E., Baghurst, K., \& van Klinken, J. W. (2004). Nutrients for cognitive development in school-aged children. Nutrition Reviews, 62(8), 295-306.

Croll, J. K., Neumark-Sztainer, D., \& Story, M. (2001). Healthy eating. What does it mean to adolescents? Journal of Nutrition Education, 33(4), 193-198.

D’Anci, K. E., Constant, F., \& Rosenberg, I. H. (2006). Hydration and Cognitive Function in Children. Nutrition Reviews, 64(10), 457-464.

Delange, F. (2001). lodine deficiency as a cause of brain damage. Postgraduate Medical Journal, 77(906), 217-220.

Dye, L., \& Blundell, J. (2002). Functional foods. Psychological and behavioural functions. British Journal of Nutrition, 88, S187-S211.

Florence, M. D., Asbridge, M., \& Veugelers, P. J. (2008). Diet Quality and Academic Performance. Journal of School Health, 78(4), 209-215.

Gibson, E. L., \& Green, M. W. (2002). Nutritional influences on cognitive function. Mechanisms of susceptibility. Nutrition Research Reviews, 15(1), 169-206. Golan, M., \& Crow, S. (2004). Parents are key players in the prevention and treatment of weight-related problems. Nutrition Reviews, 62(1), 39-50.

Graneheim, U. H., \& Lundman, B. (2004). Qualitative content analysis in nursing research. Concepts, procedures and measures to achieve trustworthiness. Nurse Education Today, 24(2), 105-112.

Grantham-McGregor, S. (2005). Can the provision of breakfast benefit school performance? Food Nutrition Bulletin, 26(Suppl 2), S144-158. 
Hart, K. H., Herriot, A., Bishop, J. A., \& Truby, H. (2003). Promoting healthy diet and exercise patterns amongst primary school children. A qualitative investigation of parental perspectives. Journal of Human Nutrition Diet, 16(2), 89-96.

Hesketh, K., Waters, E., Green, J., Salmon, L., \& Williams, J. (2005). Healthy eating, activity and obesity prevention. A qualitative study of parent and child perceptions in Australia. Health Promotion International, 20(1), 19-26.

Hoyland, A., Lawton, C. L., \& Dye, L. (2008). Acute effects of macronutrient manipulations on cognitive test performance in healthy young adults. A systematic research review. Neuroscience \& Biobehavioral Reviews, 32(1), 72-85.

Hughes, D., \& Bryan, J. (2003). The assessment of cognitive performance in children. Considerations for detecting nutritional influences. Nutrition Reviews, 61(12), 413-422.

Morley, R. (1998). Nutrition and cognitive development. Nutrition, 14(10), 752-754. Paquette, M. C. (2005). Perceptions of healthy eating. State of knowledge and research gaps. Canadian Journal of Public Health, 96(Suppl 3). S15-19, S16-21. Patton, M. Q. (1999). Enhancing the quality and credibility of qualitative analysis. [Proceedings Paper]. Health Services Research, 34(5), 1189-1208.

Pollitt, E. (1995). Does breakfast make a difference in school? Journal of American Diet Association, 95(10), 1134-1139.

Pollitt, E., \& Mathews, R. (1998). Breakfast and cognition. An integrative summary. American Journal of Clinical Nutrition, 67(4), 804s-813s.

Rampersaud, G. C., Pereira, M. A., Girard, B. L., Adams, J., \& Metzl, J. D., (2005). Breakfast habits, nutritional status, body weight, and academic performance in children and adolescents. Journal of American Diet Association, 105(5), 743-760;

Rogers, P. J. (1995). Food, mood and appetite. Nutrition Research Reviews, 8(1), 243-269.

Rozin, P., Ashmore, M., \& Markwith, M. (1996). Lay American conceptions of nutrition. Dose insensitivity, categorical thinking, contagion, and the monotonic mind. Health Psychology, 15(6), 438-447.

Ruxton, C. H. S., Gardner, E. J., \& McNnulty, H. M. (2010). Is Sugar Consumption Detrimental to Health? A Review of the Evidence 19952006. [Review]. Critical Reviews in Food Science and Nutrition, 50(1), 1-19.

Schmitt, J. A., Benton, D., \& Kallus, K. W. (2005). General methodological considerations for the assessment of nutritional influences on human cognitive functions. European Journal of Nutrition, 44(8), 459-464.

Scott-Jones, D. (1984). Family Influences on Cognitive Development and School Achievement. Review of Research in Education, 11, 259-304.

Thomas, D., Grant, S., \& Aubuchon-Endsley, N. (2009). The Role of Iron in Neurocognitive Development. [Review]. Developmental Neuropsychology, 34(2), 196-222. 
Tomlinson, D., Wilkinson, H., \& Wilkinson, P. (2009). Diet and Mental Health in Children. [Article]. Child and Adolescent Mental Health, 14(3), 148-155.

Welsh, E. (2002). Dealing with Data. Using NVivo in the Qualitative Data Analysis Process. Forum Qualitative Sozialforschung/Forum. Qualitative Social Research, 3(2), Art.26.

Westenhoefer, J., Bellisle, F., Blundell, J. E., de Vries, J., Edwards, D., Kallus, W., et al. (2004). PASSCLAIM. Mental state and performance. [Review]. European Journal of Nutrition, 43, 85-117.

Withall, J., Jago, R., \& Cross, J. (2009). Families' and health professionals' perceptions of influences on diet, activity and obesity in a low-income community. Health Place, 15(4), 1078-1085.

\section{Acknowledgements}

This research is funded by the European Community's 7th Framework Programme (FP7/2008-2013) under Grant agreement No. 212652 (NUTRIMENTHE project "The Effect of Diet on the Mental Performance of Children"). The research group would like to thank all participating schools and parents. M.R., C.C., T.D., B.K. conceived the study. The interview schedule was designed by B.E., H.G., M.R., B.B., E.G., J-CL-R, and data were gathered and analysed by B.B., B.E., E.G., J-CL-R. The paper was drafted by B.B., with assistance from B.E. and M.R. All authors have reviewed and approved the final version. The authors declare no conflicts of interest. 
Table 1. Interview structure.

\begin{tabular}{|c|c|}
\hline Questions & Prompts \\
\hline $\begin{array}{l}\text { Thinking about children in general (aged } 4-10 \text { ) } \\
\text { do you think that food has an effect on children's } \\
\text { wellbeing and development? }\end{array}$ & $\begin{array}{l}\text { In what ways does it affect children? Can you } \\
\text { give me some examples? }\end{array}$ \\
\hline $\begin{array}{l}\text { Do you think that what children eat affects them } \\
\text { physically? }\end{array}$ & $\begin{array}{l}\text { In what way does it affect them physically - } \\
\text { weight, sleep, energy levels? }\end{array}$ \\
\hline $\begin{array}{l}\text { Do you think what children eat affects their } \\
\mathrm{mood} / \text { behaviour? }\end{array}$ & How would you recognise these effects? \\
\hline $\begin{array}{l}\text { If so, how and in what ways positive and } \\
\text { negative? }\end{array}$ & $\begin{array}{l}\text { (Alertness, restlessness, calm/excited, arousal, } \\
\text { anger, fatigue, lethargy, confusion and } \\
\text { irritability) }\end{array}$ \\
\hline $\begin{array}{l}\text { Do you think that food might affect children's } \\
\text { mental performance? }\end{array}$ & $\begin{array}{l}\text { Academic performance, concentration, } \\
\text { attention, memory. }\end{array}$ \\
\hline \multicolumn{2}{|l|}{ If so, how and in what ways? } \\
\hline $\begin{array}{l}\text { Do you think that what children eat affects them } \\
\text { now or could it affect them in the future? }\end{array}$ & In what ways might food affect them? \\
\hline $\begin{array}{l}\text { Thinking about foods, are there any specific } \\
\text { foods that you think affect children, either } \\
\text { positively or negatively? }\end{array}$ & $\begin{array}{l}\text { Can you give me some examples of foods that } \\
\text { affect childrengood and/or bad effects? How do } \\
\text { you think these foods might have these effects? }\end{array}$ \\
\hline
\end{tabular}

Table 2. Characteristics of participating parents in the different European countries.

\begin{tabular}{|l|l|c|c|c|c|c|}
\hline & & \multicolumn{4}{|c|}{ Percentage of parents in } \\
\hline & & Germany & Spain & England & Hungary & Total \\
\hline Sample size, $\mathrm{n}$ & & 35 & 35 & 31 & 23 & 124 \\
\hline Number of children in the family & 1 & 17.1 & 17.1 & 16.1 & 39.1 & 21.0 \\
\hline & 2 & 62.9 & 65.7 & 45.2 & 56.5 & 58.1 \\
\hline & 3 & 11.4 & 14.3 & 25.8 & 4.3 & 14.5 \\
\hline & 4 & 8.6 & 2.9 & 9.7 & 0 & 5.6 \\
\hline & 5 & 0 & 0 & 3.2 & 0 & 0.8 \\
\hline & & & & & & \\
\hline & Yes & 60.0 & 80.0 & 71.0 & 100.0 & 75.8 \\
\hline & No & 37.1 & 20.0 & 29.0 & 0 & 23.4 \\
\hline Highest level of education completed & Missing & 2.9 & 0 & 0 & 0 & 0.8 \\
\hline & Primary school & 0 & 25.7 & 0 & 0 & 7.3 \\
\hline & Secondary school age15/16 & 5.7 & 17.1 & 16.1 & 4.3 & 11.3 \\
\hline & Secondary school age 17/18 & 37.1 & 22.9 & 3.2 & 39.1 & 23.4 \\
\hline & College & 25.7 & 20.0 & 51.6 & 30.4 & 31.5 \\
\hline & University & 31.4 & 14.3 & 29.0 & 26.1 & 25.0 \\
\hline & & & & & & \\
\hline & Mother & 5.7 & 22.9 & 9.7 & 0 & 10.5 \\
\hline & Father & & & & & \\
\hline
\end{tabular}




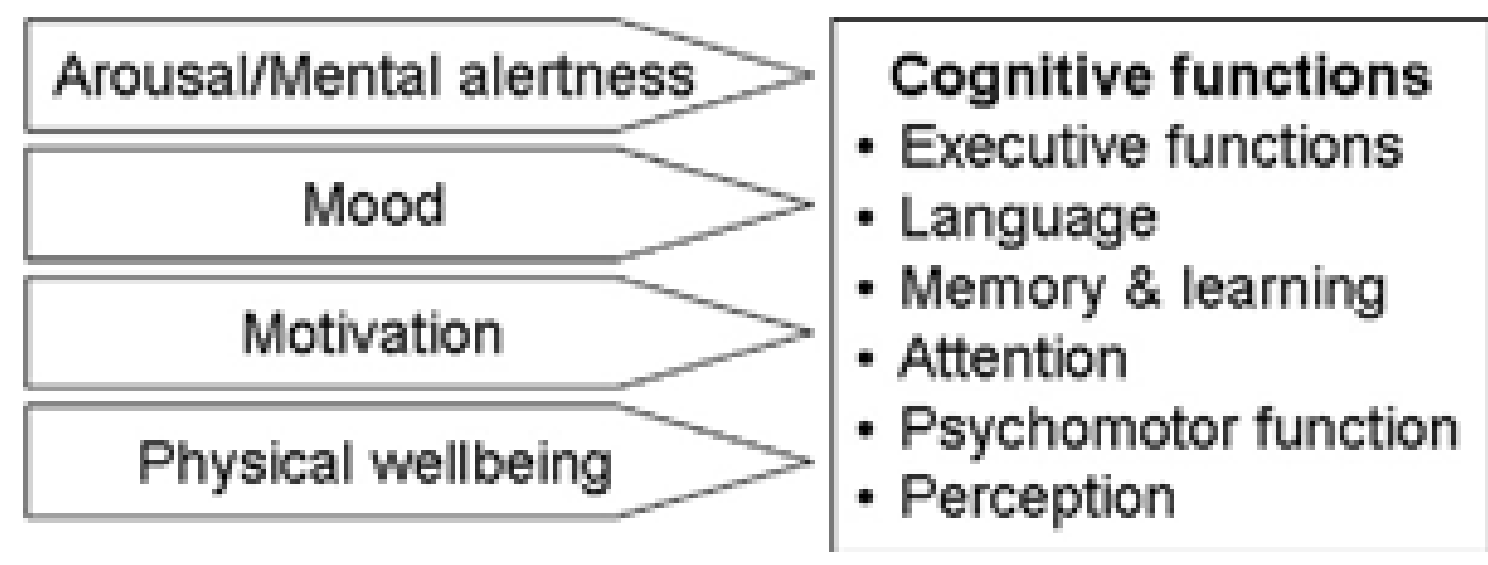

Fig. 1. Expert model of classification of cognitive functions and their modulating factors (redrawn from Schmitt et al., 2005). Cognitive functions can be classified into six areas: perception, psychomotor functions, attention, language, memory and learning and executive functions. Those functions may be modulated by different factors such as the level of arousal (mental arousal or energy), mood and motivation and physical wellbeing

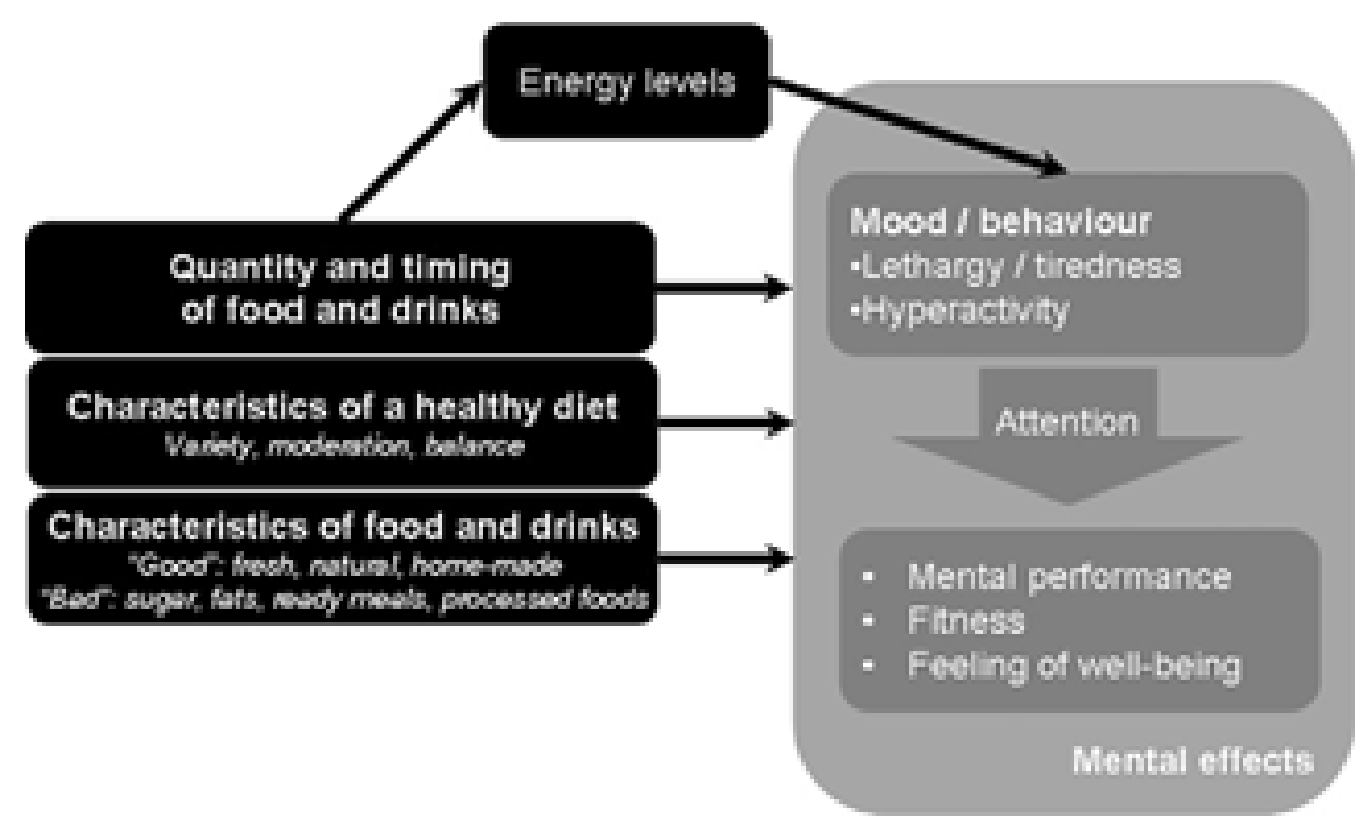

Fig. 2. Schematic representations of parental perceptions of the relationship between diet and mental outcomes in children. Effects of diet on mental performance are related to foods in specific ways: parents speak about the characteristics and quantity of foods, clearly distinguishing between "good" and "bad" foods. Positive outcomes are related to a healthy diet, with effects on mental performance, fitness and well-being. More specific effects are mainly perceived to be on attention; often mediated by a child's mood and behaviour which in turn is influenced by a child's energy level. 